\title{
Neuropsychological predictors of dependency in patients with Alzheimer disease
}

\author{
M. Sarazin, MD; Y. Stern, PhD; C. Berr, PhD; A. Riba, BA; M. Albert, PhD; J. Brandt, PhD; \\ and B. Dubois, MD
}

\begin{abstract}
Objective: To determine whether specific cognitive deficits can predict the progression of Alzheimer disease (AD). Methods: Two hundred fifty-two patients with AD enrolled in the Predictors Study were followed at 6-month intervals for up to 4.5 years with neurologic, cognitive, and psychiatric examinations. Neuropsychological functions were assessed by the Modified Mini-Mental State Examination (mMMSE). Items of mMMSE were divided into five cognitive domains: temporospatial orientation, short-term memory, long-term memory, language, and visuoconstructive functions. Loss of autonomy was assessed by both the Dependency Scale (DS) and the Equivalent Institutional Care (EIC) rating. Cox proportional hazards models, adjusted for age, sex, estimated duration of illness at entry into the study, and presence of extrapyramidal signs and behavioral disturbances, were used to determine the predictive value of each neuropsychological domain on dependency outcomes. Results: Global mMMSE, temporospatial orientation, and short-term memory scores were associated with a greater relative risk of moderate or severe dependency. The visuoconstructive score predicted the development of severe dependency. Long-term memory and language scores were not predictive of the EIC or DS endpoints. Conclusions: The presence of certain neuropsychological deficits at a patient's initial visit, such as short-term memory, temporospatial orientation, and constructive apraxia, predict more rapid dependency in patients with Alzheimer disease. Neuropsychological items have different weights in term of predictive power, and these effects are independent of the influence of age and disease duration at baseline.
\end{abstract}

NEUROLOGY 2005;64:1027-1031

In recent years, interest in factors that predict rate of functional decline in patients with Alzheimer disease $(\mathrm{AD})$ or time to reach specific outcomes has increased. It has primarily focused on demographic data such as age at onset, ${ }^{1,2}$ educational level, ${ }^{3}$ presence of clinical signs such as extrapyramidal signs ${ }^{2,4}$ (EPSs) and behavioral symptoms, ${ }^{5-7}$ and global cognitive deficit measured by the Mini-Mental State Examination (MMSE). ${ }^{8,9}$

Although the most prominent feature of $\mathrm{AD}$ is the decline in cognitive functions, the influence on functional decline of specific cognitive deficits has not been frequently studied. Longitudinal analysis of the Predictors Study showed that a higher total score of the Modified Mini-Mental State Examination (mMMSE) was predictive of reaching nursing home entry or death more slowly. ${ }^{10} \mathrm{~A}$ recent study showed that baseline level of cognition was not related to mortality, but high rate of annual global cognitive decline increased the risk of mortality. ${ }^{11}$

In fact, cognitive decline is not a uniform process. It involves alterations in different neuropsychological domains, each of them supported by specific neu- ronal networks. It is now well established that a deficit in episodic memory is the earliest and most prominent cognitive manifestation of $\mathrm{AD}$, reflecting the precocious involvement of mesial temporal structures. ${ }^{12}$ Aside from memory, patients may also demonstrate early impairment in aspects of attention and executive functions, ${ }^{13}$ visuoperceptual functions, ${ }^{13,14}$ expressive and receptive language, and the ability to plan and organize activities. ${ }^{15}$ These disorders are consistent with the secondary extension of lesions to the neocortical associative areas.

The aim of this study was to assess the sensitivity of specific neuropsychological parameters obtained at the first visit for predicting levels of dependency in $\mathrm{AD}$. Patients with $\mathrm{AD}$ were enrolled in the Predictors Study and followed longitudinally at 6-month intervals for up to 10 years. Patients were assessed with the mMMSE and with the Dependency Scale (DS) at each visit. Items of the baseline mMMSE were grouped into five cognitive domains: temporospatial orientation, short-term memory, long-term memory, language, and visuoconstructive function. We used Cox proportional hazards models to deter-

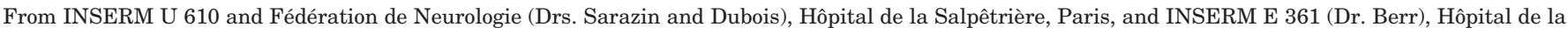

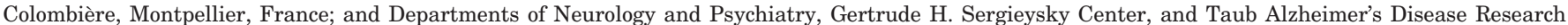

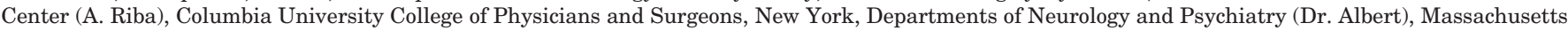

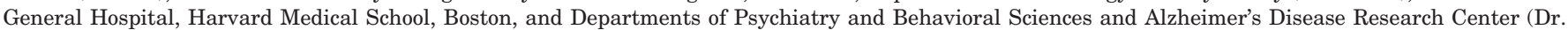
Brandt), John Hopkins University School of Medicine, Baltimore, MD.

Received March 8, 2004. Accepted in final form November 29, 2004.

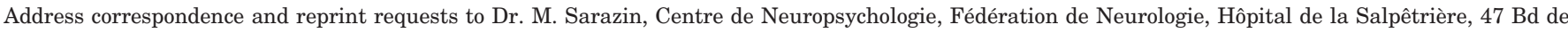
l'Hôpital, 75013 Paris, France; e-mail: marie.sarazin@brt.ap-hop-paris.fr 
mine which of these domains were predictive of reaching specific dependency endpoints. Specific functional outcomes were assessed by both the DS and the Equivalent Institutional Care (EIC) rating.

Methods. Subjects. Subjects were members of the Predictors Study cohort. ${ }^{16}$ Two hundred fifty-two patients with probable AD were recruited into the study at three different sites: Columbia University, Johns Hopkins University School of Medicine, and Massachusetts General Hospital. Details of inclusion and exclusion and recruitment methods have been previously described. ${ }^{16}$ In summary, each patient recruited had to meet National Institute of Neurological and Communication Disorders and Stroke/Alzheimer Disease and Related Disorders Association criteria for probable $\mathrm{AD}$ except for the allowance for lesions on neuroimaging described below. Intellectual impairment was documented by neuropsychological testing using the standard clinical batteries of each institution. Although diagnostic test batteries differ somewhat at each center, they all included tests of memory, orientation, abstract reasoning, language, attention, and construction. Patients had to be maintained off antipsychotic medications for at least 1 month before their initial evaluation.

Exclusion criteria were history or current clinical evidence of substance abuse, schizophrenia, schizoaffective disorder, or major affective disorder prior to the onset of intellectual decline; any electroconvulsive therapy treatment within 2 years of recruitment or $\geq 10$ lifetime electroconvulsive treatments at any time; and history or clinical signs of stroke or a Hachinski Ischemic Scale score $\geq 5$. Patients with small subcortical lesions on CT or MRI scans that were clinically and historically silent and were judged to be $<2 \mathrm{~cm}$ in diameter were included, as were those with diffuse symmetric periventricular lucencies. Patients with cortical lesions of any size or location or with focal cortical atrophy in a specific vascular distribution were excluded.

This project was approved by the institutional review board at each participating institution, and all patients or their proxies provided written informed consent.

Procedures. All patients were seen at 6-month intervals and underwent the following procedures.

Onset dating and features. At the initial visit, the physician estimated the disease duration based on interview of the patient and the informants. Disease onset was also estimated using a standardized onset interview technique that systematically queries the earliest date of manifestation of specific disease symptoms as well as the latest point at which these symptoms were not present. ${ }^{17}$

Neurologic examination. Clinical neurologic examination included selected items from the Unified Parkinson's Disease Rating Scale described in a previous article. ${ }^{4}$ Rated EPSs included tremor, rigidity, bradykinesia, gait, posture change, and facial appearance. For all statistical analyses that used EPSs, patients who had at least one sign rated as mild to moderate (rated score 2) were considered to have EPSs.

Neuropsychological assessment. Cognitive function was examined using the mMMSE. ${ }^{18,19}$ This instrument included all items from the standard MMSE ${ }^{20}$ plus the Wechsler Adult Intelligence Scale-revised Digit Span Subtest ${ }^{21}$ and additional attention/ calculation and general knowledge, language, and construction items. The maximum score on the mMMSE is 57. Test-retest reliability is high $(r=0.95)$, and correlations with the original MMSE $(r=0.89)$, the Blessed Memory Information Concentration Test $(r=0.93)$, and Full-Scale IQ $(r=0.66)$ are indicative of adequate validity. ${ }^{22}$ For the current analysis, the items on the mMMSE were grouped to define five major cognitive domains: temporospatial orientation, short-term memory, long-term memory, language, and visuoconstructive domains. Items assessing temporospatial orientation were those of the standard MMSE and led to a maximum score of 10 . Short-term memory consisted of immediate recall of three words, Forward and Backward Digit Span Subtests, and attention/calculation items with a maximal score of 20. Long-term memory consisted of delayed recall of three words (10-minute delay recall) and general knowledge items (names of the five previous presidents). Maximum score of longterm memory was 8 . Language was assessed by items from the standard MMSE and confrontation naming of 10 items from the Boston Naming Test, for a maximum score of 17 . Visuoconstruc- tive abilities were assessed by copying two figures and were rated from 0 to 2 .

Functional assessment. Functional capacity was rated with Parts 1 and 2 of the Blessed Dementia Rating Scale (BDRS), whose reliability and validity have been established. ${ }^{23}$ Moreover, it has been shown useful in evaluating longitudinal changes in function.

Dependency assessment. Level of dependency was assessed by the DS, which rates the patient's need for care. ${ }^{24}$ It is based on interview data and summarizes the interviewer's impression of the care the patient received and required, regardless of location. Maximum score is 5. The EIC was established from the second section of the DS. Categories include limited home care, adult home (a supervised setting with regular assistance in most activities), and health-related facility. Maximal score is 3. Previous studies have demonstrated the robust validity of these scales..$^{11,25}$

Data analyses. Cox analysis. Cox analyses focused on the five cognitive domains evaluated by the mMMSE. The outcomes of severity of the disease were defined by two stages of clinical dependency in every day life. Moderate dependency was defined as reaching a score of 2 on the EIC (patient needing a supervised setting with regular assistance in most activities) and a score of 3 on the DS (patient needing to be watched when awake). Severe dependency was defined as reaching a score of 3 on the EIC (patient needing health-related facility) and a score of 4 on the DS (patient needing to be dressed, watched, and fed). For each combination of predictor and outcome, we calculated a Cox proportional hazards model that used months from the initial visit as the time variable. All Cox analyses were adjusted for estimated duration of illness, sex, and education level. In addition, as preliminary analyses revealed that age and EPSs influence survival, Cox analyses were also adjusted for these variables.

Comparisons of initial cognitive performance between the group of patients that did and did not reach dependency. We defined a group of patients that did not develop moderate dependency (score below 3 on the DS) and a group that reached this endpoint at 1 and 2 years. We compared their cognitive performance at the initial visit. One hundred three patients at 1 year of follow-up and 57 patients at 2 years were not dependent; although 116 patients at 1 year and 121 at 2 years were moderately dependent.

Results. Clinical characteristics at baseline. At study entry, mean patient age was $72.8 \pm 8.9$ (mean \pm SD) years with a sex ratio $(\mathrm{M} / \mathrm{F})$ of $41 / 59$. Education level was $13.1 \pm$ 3.6 years. At the baseline visit, the mean estimated duration of illness was $2.3 \pm 2.2$ years. Score on the DS was $2.3 \pm 0.8$ and on the EIC $1.5 \pm 0.6$. Mean scores of the BDRS were $3.3 \pm 1.4$ on Part 1 and $0.5 \pm 0.9$ on Part 2. All patients $(\mathrm{n}=252)$ were followed for at least 6 months, 219 for $\geq 1$ year, 178 for $\geq 2$ years, 159 for $\geq 3$ years, and 125 for $\geq 4$ years. Mean mMMSE score at inclusion was $37.1 \pm 6.2$. Temporospatial orientation score was $6 \pm 2.3$ (maximum $=$ 10 ), long-term memory score $1.9 \pm 1.6$ (maximum $=8$ ), short-term memory score $14.8 \pm 3.3$ (maximum $=20$ ), language score $13.6 \pm 2.4$ (maximum $=17$ ), and visuoconstructive score $0.9 \pm 0.8$ (maximum $=2$ ).

Cox analysis. Analysis of the data was performed on the four major endpoints assessing moderate and severe dependency.

Moderate dependency. Global cognitive efficiency, measured by total score of the mMMSE, was associated with an elevated risk of reaching moderate dependency as defined by the EIC (table 1). Temporospatial orientation and short-term memory scores were associated with nursing home care. Long-term memory, language, and visuoconstructive scores were not associated with an elevated relative risk $(\mathrm{RR})$ of reaching this endpoint.

Global cognitive efficiency, measured by the total score of the mMMSE, was associated with elevated risk of reaching moderate dependency as defined by the DS score. The 


\begin{tabular}{|c|c|c|c|c|}
\hline \multirow[b]{3}{*}{ Predictor } & \multicolumn{2}{|c|}{ Moderate dependency } & \multicolumn{2}{|c|}{ Severe dependency } \\
\hline & $\begin{array}{l}\text { Institutional care } \\
\text { rating }\end{array}$ & Dependency & $\begin{array}{l}\text { Institutional } \\
\text { care rating }\end{array}$ & Dependency \\
\hline & $\mathrm{RR}(95 \% \mathrm{CI})$ & $\mathrm{RR}(95 \% \mathrm{CI})$ & $\mathrm{RR}(95 \% \mathrm{CI})$ & $\mathrm{RR}(95 \% \mathrm{CI})$ \\
\hline Total mMMSE & $1.59(1.28-1.97)^{*}$ & $1.45(1.22-1.74)^{*}$ & $1.38(1.16-1.63) \dagger$ & $1.44(1.21-1.70)^{*}$ \\
\hline TS orientation & $1.82(1.23-2.70) \dagger$ & $1.93(1.36-2.74) \dagger$ & $1.57(1.13-2.18) \ddagger$ & $1.68(1.20-2.36) \dagger$ \\
\hline Long-term memory & $1.37(0.89-2.11)$ & $1.26(0.86-1.86)$ & $1.15(0.81-1.65)$ & $1.01(0.70-1.44)$ \\
\hline Short-term memory & $2.4(1.56-3.69)^{*}$ & $1.96(1.36-2.74) \dagger$ & $1.66(1.18-2.33) \dagger$ & $1.65(1.18-2.31) \dagger$ \\
\hline Language & $1.25(0.82-1.93)$ & $1.32(0.93-1.88)$ & $1.30(0.93-1.82)$ & $1.37(0.97-1.92)$ \\
\hline Construction & $1.26(0.78-2.03)$ & $1.14(0.78-1.68)$ & $1.61(1.10-2.35) \ddagger$ & $1.61(1.10-2.36) \ddagger$ \\
\hline
\end{tabular}

Analysis was adjusted for age, duration of illness, sex, presence of extrapyramidal signs; and education level.

$* p<0.0001$.

$\dagger p<0.005$.

$\ddagger p<0.01$.

$\mathrm{RR}=$ relative risk; $\mathrm{mMMSE}=$ Modified Mini-Mental State Examination; $\mathrm{TS}=$ temporospatial.

same cognitive domains that were predictors for the nursing home care endpoint proved to be significant for the DS. Temporospatial orientation and short-term memory scores were associated with higher occurrence of dependency. Long-term memory, language, and visuoconstructive scores were not associated with an increased $R R$ of reaching this endpoint.

Severe dependency. Global mMMSE, temporospatial orientation, and short-term memory scores were robust predictors of reaching severe dependency as defined by the EIC and were also robust predictors of severe dependency defined by the DS (see table 1 ). In addition, the visuoconstructive score was a predictor of severe dependency, as defined by the EIC and the DS. Long-term memory and language scores were not predictive of the EIC or DS endpoints.

Comparisons of initial cognitive performance between groups that did and did not develop dependency. We compared neuropsychological scores at the initial visit between patients who developed moderate dependency 1 year later $(\mathrm{n}=116)$ and those who did not $(\mathrm{n}=103)$ (table 2$)$. The two groups differed in scores on the mMMSE, temporospa- tial orientation, and short-term memory. The other neuropsychological scores (in particular, long-term memory, language, and visuoconstructive scores) did not differ between the two groups. At 2 years of follow up, we found the same pattern of results: The two groups (121 "dependent" patients and 57 "nondependent" patients) differed in scores on the mMMSE, temporospatial orientation, and shortterm memory, while the other neuropsychological scores did not differ.

Discussion. Several strengths of the study should be noted. The cohort was large and followed at regular intervals for a long period of time. Patients were recruited from different medical centers, diminishing the risk of a center effect both for the diagnostic procedure and for the identification of predictors. Dependency was assessed with valid scales. Using nursing home care as a study endpoint was more useful than using the entry into a nursing home itself. ${ }^{10}$ The DS measures the amount of assistance that patients with dementia require to perform daily

Table 2 Comparisons of initial cognitive performance between groups that did and did not develop dependency

\begin{tabular}{|c|c|c|c|c|c|c|}
\hline \multirow[b]{2}{*}{ Initial score } & \multicolumn{3}{|c|}{1 year of follow-up } & \multicolumn{3}{|c|}{2 years of follow-up } \\
\hline & $\begin{array}{c}\text { Dependency } \\
+\end{array}$ & $\begin{array}{c}\text { Dependency } \\
-\end{array}$ & $p$ & $\begin{array}{c}\text { Dependency } \\
+\end{array}$ & $\begin{array}{c}\text { Dependency } \\
-\end{array}$ & $p$ \\
\hline Total mMMSE & $35.8 \pm 5.0$ & $39.6 \pm 6.1$ & $<0.0001$ & $37.5 \pm 5.7$ & $40.8 \pm 6.2$ & $<0.0001$ \\
\hline TS orientation & $5.7 \pm 2.2$ & $6.5 \pm 2.2$ & 0.0002 & $6.2 \pm 2$ & $7.2 \pm 2$ & 0.01 \\
\hline Language & $13.5 \pm 2.0$ & $14.1 \pm 23$ & NS & $14.1 \pm 2.1$ & $14.5 \pm 2.4$ & NS \\
\hline Construction & $0.8 \pm 0.7$ & $1.0 \pm 0.8$ & NS & $0.8 \pm 0.9$ & $1.2 \pm 0.7$ & NS \\
\hline
\end{tabular}

Analysis was adjusted for age, duration of the illness, sex, presence of extrapyramidal signs, and education level.

Dependency $+=$ patients who had developed moderate dependency; Dependency $-=$ patients who had not developed moderate dependency; mMMSE = Modified Mini-Mental State Examination; TS = temporospatial. 
activities. ${ }^{24}$ The EIC rating, used as an endpoint in this study, was based on several measures of activities of daily living that reflect the real needs of patients at home. Whereas the neuropsychological data were not as comprehensive as in more detailed neuropsychological studies, they reflect the kind of data available to practicing neurologists and therefore constitute more practical information for them.

As previously described, the level of global cognitive impairment was a risk factor for dependency and placement.,4 Furthermore, this study showed that the various cognitive domains had different weights in terms of predictive power. A lower score in temporospatial orientation and in short-term memory was associated with a higher risk of reaching moderate and severe dependency sooner, and a lower score in visuoconstructive function was also associated with a higher risk of reaching severe dependency. By contrast, language and long-term memory performance were not predictive of dependency. These findings are in agreement with the fact that differences in the rate of progression of neuropsychological deficits are directly related to the progression of the underlying cerebral lesions. Indeed, spatial and temporal progression of $\mathrm{AD}$ neuropathology is directly responsible for the emergence of cognitive and behavioral changes, which can be linked to the decline of functional capacity.

The fact that long-term memory score was not predictive of dependency is not surprising. Longterm memory is the central core of the disease and occurs in its early stages. ${ }^{26}$ An amnesic syndrome of the "hippocampal" type is highly suggestive of $\mathrm{AD} .{ }^{27}$ This is consistent with the precocious involvement of mesial temporal structures, as demonstrated by postmortem evidence ${ }^{28}$ and by morphometric MRI in mildly affected patients ${ }^{29,30}$ or in patients with mild cognitive impairment who subsequently developed AD. ${ }^{31}$ As a consequence, long-term memory performance has a rapid floor effect in follow-up studies, as been previously noted with the delayed recall score of the MMSE and the Mattis Dementia Rating Scale. ${ }^{32}$ This precocious involvement of mesial temporal structures may also explain why long-term memory is a robust predictor of dementia in patients with mild cognitive impairment ${ }^{2,33}$ and in nondemented elderly subjects..$^{33,34}$

Lower short-term memory score at first visit was predictor of moderate and severe dependency. It does not seem to result from the relative weight of the short-term memory items in mMMSE (maximal score of 20/57) because language evaluation has approximately the same weight $(17 / 57)$ and no predictive power. The role of short-term memory as a predictive factor might result from the fact that it involves attentional resources that are considered to represent the central executive component within the theoretical framework of working memory. ${ }^{35} \mathrm{~Pa}-$ tients with mild $\mathrm{AD}$ are impaired in the functioning of the central executive component of working memory, particularly when patients are required to per- form two concurrent tasks simultaneously, a common feature of everyday activities. ${ }^{36}$ This may explain why impairment in short-term memory implies more functional consequence in routine activities of daily living than language or visuospatial impairment.

Temporal and spatial disorientation was associated with a high risk of reaching dependency. Previous studies showed that this neuropsychological deficit occurs early in the course of the disease ${ }^{33,37,38}$ and probably reflects a degeneration of the pathways linking the hippocampus with the superior parietal and posterior cingulate cortex. ${ }^{39}$ Autonomy, defined by the capacity to act without assistance, directly depends on the ability to refer oneself spatially and temporally. Temporospatial orientation therefore plays an important role in everyday activities, and when it deteriorates, caregivers' assistance is required. These results suggest that temporospatial orientation should be more carefully studied in the future as it may be relevant in terms of risk of dependency.

The visuoconstructive score, assessed with only one component of visuoconstructive ability (figures copy), predicted severe dependency. Disturbances of visuospatial constructive functions are well recognized in $\mathrm{AD}$ and closely related to the pathologic changes in posterior temporoparietal and occipital associative areas and to the reductions in regional cerebral perfusion and regional metabolic changes in these same cortical areas. ${ }^{29,40-42}$ Our results fit well with a previous study showing that constructive apraxia was a predictor of accelerated cognitive decline. ${ }^{41}$ This suggests that, more than language (which is not a predictive factor), visuoconstructive abilities provoke a severe dependency outcome because the integrity of visuospatial and praxic functions, which both rely on parietal lobe function, is involved in daily activities.

In future research on a larger sample, it would be beneficial to better understand the combined effects of all predictors described in $\mathrm{AD}$ to inform and help family to prepare for care.

\section{References}

1. Jacobs D, Sano M, Marder K, et al. Age at onset of Alzheimer's disease: relation to pattern of cognitive dysfunction and rate of decline. Neurology 1994;44:1215-1220.

2. Devanand DP, Folz M, Gorlyn M, Moeller JR, Stern Y. Questionable dementia: clinical course and predictors of outcome. J Am Geriatr Soc 1997;57:321-238.

3. Stern Y, Tang MX, Denaro J, Mayeux R. Increase risk of mortality in $\mathrm{AD}$ patients with more advanced educational and occupational attainment. Ann Neurol 1995;37:390-595.

4. Stern Y, Albert M, Brandt J, et al. Utility of extrapyramidal signs and psychosis as predictors of cognitive and functional decline, nursing home admission, and death in Alzheimer's disease: prospective analyses from the Predictors Study. Neurology 1994;44:2300-2307.

5. Mortimer JA, Ebbitt B, Jun SP, Finch MD. Predictors of cognitive and functional progression in patients with probable Alzheimer's disease. Neurology 1992;42:1689-1696.

6. Mega MS, Cummings JL, Fiorello T, Gornbein J. The spectrum of behavioural changes in Alzheimer's disease. Neurology 1996;46:130135.

7. Lopez OL, Wisniewski SR, Becker JT, Boller F, Dekosky ST. Psychiatric medication and abnormal behavior as predictors of progression in probable Alzheimer's disease. Arch Neurol 1999;56:1266-1272. 
8. Heyman A, Wilkinson WE, Hurwitz BJ, et al. Early-onset Alzheimer's disease: clinical predictors of institutionalization and death. Neurology 1987;37:980-984.

9. Smith GE, O'Brien PC, Ivnik RJ, Kokmen E, Tangalos EG. Prospective analysis of risk factors for nursing home placement of dementia patients. Neurology 2001;57:1467-1473.

10. Stern Y, Tang MX, Albert MS, et al. Predicting time to nursing home care and death in individuals with Alzheimer disease. JAMA 1997;277: $806-812$.

11. Hui JS, Wilson RS, Bennett DA, Bienias JL, Gilley DW, Evans DA. Rate of cognitive decline and mortality in Alzheimer's disease. Neurology 2003;61:1356-1361.

12. Weinstraub S, Mesulam M. Four neuropsychological profiles in dementia. In: Bohen F, Grafman J, eds. Handbook of neuropsychology. Amsterdam: Elsevier, 1993:253-282.

13. Reid W, Broe G, Creasey H, et al. Age at onset and pattern of neuropsychological impairment in mild early-stage Alzheimer's disease. A study of a community-based population. Arch Neurol 1996;53:1056-1061.

14. Perry RJ, Hodges JR. Fate of patients with questionable (very mild) Alzheimer's disease: longitudinal profiles of individuals subjects' decline. Dement Geriatr Cogn Disord 2000;11:342-349.

15. Welsh KA, Butters N, Hughes JP, et al. Detection and staging of dementia in Alzheimer's disease. Use of the neuropsychological measures developed for the Consortium to Establish a Registry for Alzheimer's Disease. Arch Neurol 1992;49:448-452.

16. Stern Y, Folstein M, Albert M, et al. Multicenter study of predictors of disease course in Alzheimer disease (the "Predictors Study"). I. Study design, cohort description, and intersite comparisons. Alzheimer Dis $1993 ; 7: 3-21$.

17. Sano M, Stern Y, Mayeux R, Hartman S, Devanand DP. A standardized technique for establishing the onset symptoms of probable Alzheimer's disease. J Clin Exp Neuropsychol 1987;9:65.

18. Mayeux R, Stern Y, Rosen J, Leventhal J. Depression, intellectual impairment and Parkinson disease. Neurology 1981;31:645-650.

19. Stern Y, Mayeux R, Sano M, Hauser WA, Bush T. Predictors of disease course in patients with probable Alzheimer's disease. Neurology 1987; 37:1649-1653.

20. Folstein MF, Folstein SE, McHugh PR. "Mini-Mental State.” A practical method for grading the cognitive state of patients for the clinician. J Psychiatr Res 1975;12:189-198.

21. Wechsler D. Wechsler Adult Intelligence Scale-revised. New York: Psychological Corp., 1981.

22. Stern Y, Sano M, Paulsen J, Mayeux R. Modified Mini-Mental State Examination: validity and reliability. Neurology. 1987;37(suppl 1):179. Abstract.

23. Blessed G, Tomlinson BE, Roth M. The association between quantitative measures of senile changes in the cerebral grey matter of elderly subjects. Br J Psychol 1968;114:797-811.

24. Stern Y, Albert SM, Sano M, et al. Assessing patient dependence in Alzheimer's disease. J Gerontol 1994;49:M216-M222.

25. Brickman AM, Riba A, Bell K, et al. Longitudinal assessment of patient dependence in Alzheimer disease. Arch Neurol 2002;59:1304-1308.

26. Dubois B. "Prodromal Alzheimer's disease": a more useful concept than mild cognitive impairment? Curr Opin Neurol 2000;13:367-369.
27. Tounsi H, Deweer B, Ergis AM, et al. Sensitivity to semantic cuing: an index of episodic memory dysfunction in early Alzheimer disease. Alzheimer Dis 1999;13:38-46.

28. Braak H, Del Tredici K, Schultz C, Braak E. Vulnerability of select neuronal types to Alzheimer disease. Ann NY Acad Sci 2000;924:53-61.

29. Scahill RJ, Schott JM, Stevens JM, Rossor MN, Fox NC. Mapping the evolution of regional atrophy in Alzheimer's disease: unbiased analysis of fluid-registered serial MRI. Proc Natl Acad Sci USA 2002;99:47034707.

30. Fox NC, Warrington EK, Rossor MN. Serial magnetic resonance imaging of cerebral atrophy in preclinical Alzheimer's disease. Lancet 1999; 353:2125.

31. Jack CR Jr, Petersen RC, Xu Y, et al. Rates of hippocampal atrophy correlate with change in clinical status in aging and AD. Neurology 2000;55:484-489.

32. Galasko DR, Gould RL, Abramson IS, Salmon DP. Measuring cognitive change in a cohort of patients with Alzheimer's disease. Stat Med 2000; 19:1421-1432.

33. Small BJ, Fratiglioni L, Viitanen M, Winblad B, Bäckman L. The course of cognitive impairment in preclinical Alzheimer disease: threeand 6-year follow-up of a population-based sample. Arch Neurol 2000; $57: 839-844$

34. Grober E, Lipton R, Hall C, Crystal H. Memory impairment on free and cued selective reminding predicts dementia. Neurology 2000;54:827832.

35. Cherry BJ, Buckwalter JG, Henderson VW. Better preservation of memory span relative to supraspan immediate recall in Alzheimer's disease. Neuropsychologia 2002;40:846-852.

36. Baddeley AD, Bressi S, Della Sala S, Logie R, Spinnler H. The decline of working memory in Alzheimer's disease. A longitudinal study. Brain 1991;114:2521-2542.

37. Aevarson O, Skoog I. A longitudinal population study of the MMSE in the very old: relation to dementia and education. Dement Geriatr Cogn Disord 2000;11:166-115.

38. Braekhus A, Laake K, Engelad K. The Mini-Mental State Examination: identifying the most efficient variables for detecting cognitive impairment in the elderly. J Am Geriatr Soc 1992;40:1139-1145.

39. Giannakopoulos P, Gold G, Duc M, Michel JP, Hof PR, Bouras C. Neural substrates of spatial and temporal disorientation in Alzheimer's disease. Acta Neuropathol (Berl) 2000;100:189-195.

40. Chantal S, Labelle M, Bouchard RW, Braun CM, Boulanger Y. Correlation of regional proton magnetic resonance spectroscopic metabolic changes with cognitive deficits in mild Alzheimer disease. Arch Neurol 2002;59:955-962.

41. Smith MZ, Esiri MM, Barnetson L, King E, Nagy Z. Constructional apraxia in Alzheimer's disease: association with occipital lobe pathology and accelerated cognitive decline. Dement Geriatr Cogn Disord 2001;12: 281-288.

42. Boxer AL, Kramer JH, Du AT, et al. Focal right inferotemporal atrophy in Alzheimer's disease with disproportionate visual constructive impairment. Neurology 2003;61:1485-1491.

\section{DID YOU KNOW. .}

... you can browse by subspecialty topics on www.neurology.org?

Go to: http://www.neurology.org/collections and click on the specific topic for a complete list of articles. 


\section{Neurology}

Neuropsychological predictors of dependency in patients with Alzheimer disease M. Sarazin, Y. Stern, C. Berr, et al.

Neurology 2005;64;1027-1031

DOI 10.1212/01.WNL.0000154529.53488.30

This information is current as of March 21, 2005

\section{Updated Information \& Services}

References

Citations

Subspecialty Collections

Permissions \& Licensing

Reprints including high resolution figures, can be found at: http://www.neurology.org/content/64/6/1027.full.html

This article cites 37 articles, 15 of which you can access for free at: http://www.neurology.org/content/64/6/1027.full.html\#\#ref-list-1

This article has been cited by 1 HighWire-hosted articles: http://www.neurology.org/content/64/6/1027.full.html\#\#otherarticles

This article, along with others on similar topics, appears in the following collection(s):

All Neuropsychology/Behavior http://www.neurology.org//cgi/collection/all_neuropsychology_behavio $\mathrm{r}$

Alzheimer's disease

http://www.neurology.org//cgi/collection/alzheimers_disease

Information about reproducing this article in parts (figures,tables) or in its entirety can be found online at:

http://www.neurology.org/misc/about.xhtml\#permissions

Information about ordering reprints can be found online:

http://www.neurology.org/misc/addir.xhtml\#reprintsus

Neurology $®$ is the official journal of the American Academy of Neurology. Published continuously since 1951, it is now a weekly with 48 issues per year. Copyright. All rights reserved. Print ISSN: 0028-3878. Online ISSN: 1526-632X.

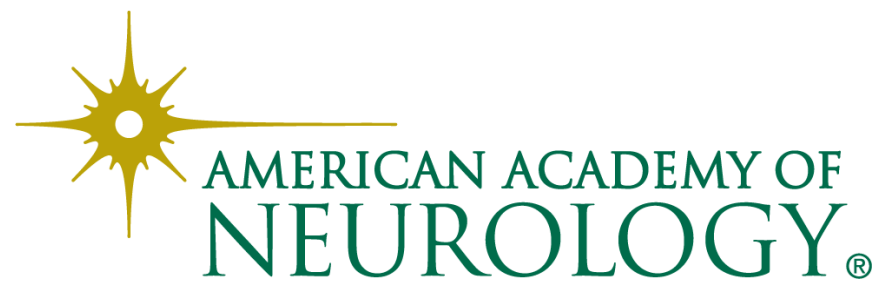

